\title{
Corrigendum: The TNF Paradox in Cancer Progression and Immunotherapy
}

\author{
Anne Montfort ${ }^{1}$, Céline Colacios ${ }^{1,2}$, Thierry Levade ${ }^{1,2,3}$, Nathalie Andrieu-Abadie ${ }^{1}$, \\ Nicolas Meyer ${ }^{1,2,4}$ and Bruno Ségui ${ }^{1,2 *}$ \\ ${ }^{1}$ INSERM UMR 1037, Cancer Research Center of Toulouse (CRCT), Toulouse, France, ${ }^{2}$ Université Toulouse III - Paul \\ Sabatier, Toulouse, France, ${ }^{3}$ Laboratoire de Biochimie, Institut Fédératif de Biologie, CHU Purpan, Toulouse, France, \\ ${ }^{4}$ Dermatologie, Institut Universitaire du Cancer (IUCT-O) et CHU de Toulouse, Toulouse, France
}

Keywords: tumor necrosis factor (TNF), PD-1, CTLA-4, melanoma, immune escape

\section{A Corrigendum on}

The TNF Paradox in Cancer Progression and Immunotherapy

by Montfort, A., Colacios, C., Levade, T., Andrieu-Abadie, N., Meyer, N., and Ségui, B. (2019). Front. Immunol. 10:1818. doi: 10.3389/fimmu.2019.01818

In the original article, there was an error. We stated that Infliximab is "a first-generation humanized TNF blocking antibody," instead of "a first-generation chimeric TNF blocking antibody."

A correction has been made to the section Combining TNF Blockade to Immune Checkpoint Blockers to Treat Melanoma, paragraph one:

"Although melanomas represent only $1 \%$ of all skin cancers, they are responsible for the majority

\section{OPEN ACCESS}

Approved by:

Frontiers Editorial Office,

Frontiers Media SA, Switzerland

${ }^{*}$ Correspondence:

Bruno Ségui

bruno.segui@inserm.fr

Specialty section:

This article was submitted to

Cancer Immunity and Immunotherapy,

a section of the journal

Frontiers in Immunology

Received: 07 October 2019 Accepted: 08 October 2019

Published: 22 October 2019

Citation:

Montfort A, Colacios C, Levade T,

Andrieu-Abadie N, Meyer N and Ségui B (2019) Corrigendum: The TNF Paradox in Cancer Progression and Immunotherapy

Front. Immunol. 10:2515 doi: 10.3389/fimmu.2019.02515 of skin cancer deaths. The use of immune checkpoint inhibitors (ICI) considerably improved the prognosis for metastatic melanoma patients with an overall survival of $58 \%$ at 3 years when treated with a combination of anti-PD-1 (Nivolumab), and anti-CTLA4 (Ipilimumab) (30). However, median progression-free survival is still only 11.5 months with nearly all patients experiencing mild to severe (grade 3/4) immune-related adverse events (irAE) (Figure 1). Interestingly, Infliximab, a first-generation chimeric TNF blocking antibody is currently being used in the clinic to treat some of the irAEs, mainly colitis, sometimes triggered by ICI (31). The impact anti-TNF antibodies have on anti-cancer immune responses in these settings are not known. A recent study indicates that $1 \%$ of patients with advanced melanoma treated by ICI develop severe colitis, which can be efficiently cured with one infliximab infusion in most of the patients, without affecting disease outcome (32). A clinical study evaluating the tolerability of infliximab in advanced cancer patients shows no dose-limiting toxic (DLT) effects and no evidence of disease acceleration in any patient. Moreover, 7 out of 41 patients experienced disease stabilization, including 1 metastatic melanoma patient (33). Other studies indicate the safety and tolerability of administering anti-TNF (etanercept or infliximab) in cancer patients affected with ovarian cancer (34), or renal cell carcinoma (35)."

The authors apologize for this error and state that this does not change the scientific conclusions of the article in any way. The original article has been updated.

Copyright (c) 2019 Montfort, Colacios, Levade, Andrieu-Abadie, Meyer and Ségui. This is an open-access article distributed under the terms of the Creative Commons Attribution License (CC BY). The use, distribution or reproduction in other forums is permitted, provided the original author(s) and the copyright owner(s) are credited and that the original publication in this journal is cited, in accordance with accepted academic practice. No use, distribution or reproduction is permitted which does not comply with these terms. 